\title{
Evaluation of the ability of an artificial neural network model to assess the variation of groundwater quality in an area of blackfoot disease in Taiwan
}

\author{
Yi-Ming Kuo, Chen-Wuing Liu*, Kao-Hung Lin \\ Department of Bioenvironmental Systems Engineering, National Taiwan University, Taipei, Taiwan, 10617, ROC
}

Received 20 June 2003; received in revised form 15 August 2003; accepted 7 September 2003

\begin{abstract}
The back-propagation (BP) artificial neural network (ANN) is applied to forecast the variation of the quality of groundwater in the blackfoot disease area in Taiwan. Three types of BP ANN models were established to evaluate their learning performance. Model A included five concentration parameters as input variables for seawater intrusion and three concentration parameters as input variables for arsenic pollutant, respectively, whereas models B and C used only one concentration parameter for each. Furthermore, model C used seasonal data from two seasons to train the ANN, whereas models $\mathrm{A}$ and $\mathrm{C}$ used only data from one season. The results indicate that model $\mathrm{C}$ outperforms models $\mathrm{A}$ and B. Model $\mathrm{C}$ can describe complex variation of groundwater quality and be used to perform reliable forecasting. Moreover, the number of hidden nodes does not significantly influence the performance of the ANN model in training or testing.
\end{abstract}

(C) 2003 Elsevier Ltd. All rights reserved.

Keywords: Arsenic pollutant; Groundwater quality; Artificial neural network; Back-propagation

\section{Introduction}

The artificial neural network (ANN), as its name implies, is a technique for the human brain's problemsolving process. Just as humans apply knowledge gained from experience to new problems or situations, the structure of a neural network can be applied to powerful computation of complex nonlinear relationships.

ANNs have been used to model groundwater, assess quality of water, forecast precipitation, predict streamflow, and support other hydrologic applications. Cabrera-Mercader and Staelin [1] used ANNs to identify cloud segmentation from microwave imagery. Raman and Chandramouli [2] adopted similar ANNs as alternative tools for deriving the general operating policy of reservoirs. Lek et al. [3] applied ANNs to predict the concentration of nitrogen in streams

\footnotetext{
*Corresponding author. Tel.: + 886-2-23626480; fax: + 8862-23629557.

E-mail address: 1cw@gwater.agec.ntu.edu.tw (C.-W. Liu).
}

from watershed features. Wen and Lee [4] were addressed the multi-objective optimization of water pollution control and river pollution planning, for the Tou-Chen river basin in Taiwan. Rogers and Dowla [5] employed an ANN, trained by a solute transport model, to perform optimization of groundwater remediation.

This study evaluates the performance of ANN models in assessing the variation of quality of groundwater and the future trends of groundwater pollution in the YunLin coastal area in Taiwan. Thirteen types of data on groundwater quality, obtained from 28 monitoring wells in the Yun-Lin coastal area of Taiwan between 1992 and 1998, were analyzed. The forecasting performance obtained by inputting one season of data into the ANN model is compared with that obtained by inputting two seasons of data. The numbers of input parameters and neurons in the hidden layer are also evaluated. The results of the study provide a basis of the evaluation tools that use ANNs, for forecasting variations in the quality of field groundwater. 


\section{Study area}

Yun-Lin County is located in the southwestern part of the alluvial fan of the Chou-Shui River (Fig. 1) in Taiwan. The area is enclosed by the Taiwan Strait to the west, the central mountains to the east, the Chou-Shui River to the north and the Pei-Kong River to the south. Chou-Shui and Pei-Kong are the two major rivers that flow through the area. The area is approximately $1000 \mathrm{~km}^{2}$, and extends $48 \mathrm{~km}$ from east to west and $24 \mathrm{~km}$ from north to south. The average annual precipitation is $1417 \mathrm{~mm}$. Rainfall is concentrated in the five-month period from May to September.

Agriculture is the primary source of revenue in YunLin. The industrial sector has grown rapidly, causing the mean income of farmers to fall significantly below that of workers in other sectors. Therefore, many farmers have converted their croplands into fishponds to boost earnings. A large quantity of groundwater has been extracted from aquifers to supply these fishponds. The extraction has caused serious land subsidence, seawater intrusion, flooding and deterioration of the surrounding environment [6,7]. Furthermore, the coastal groundwater also contains a high concentration of arsenic, and thus groundwater was used domestically, causing the local people to suffer from blackfoot disease [8].

Inhabitants of the coastal area of Yun-Lin now drink tap water; however, the groundwater is still used for aquaculture. Variations in arsenic concentration are important since groundwater intensively pumped for aquacultural uses may enter the food-chain and trigger blackfoot disease again [9].

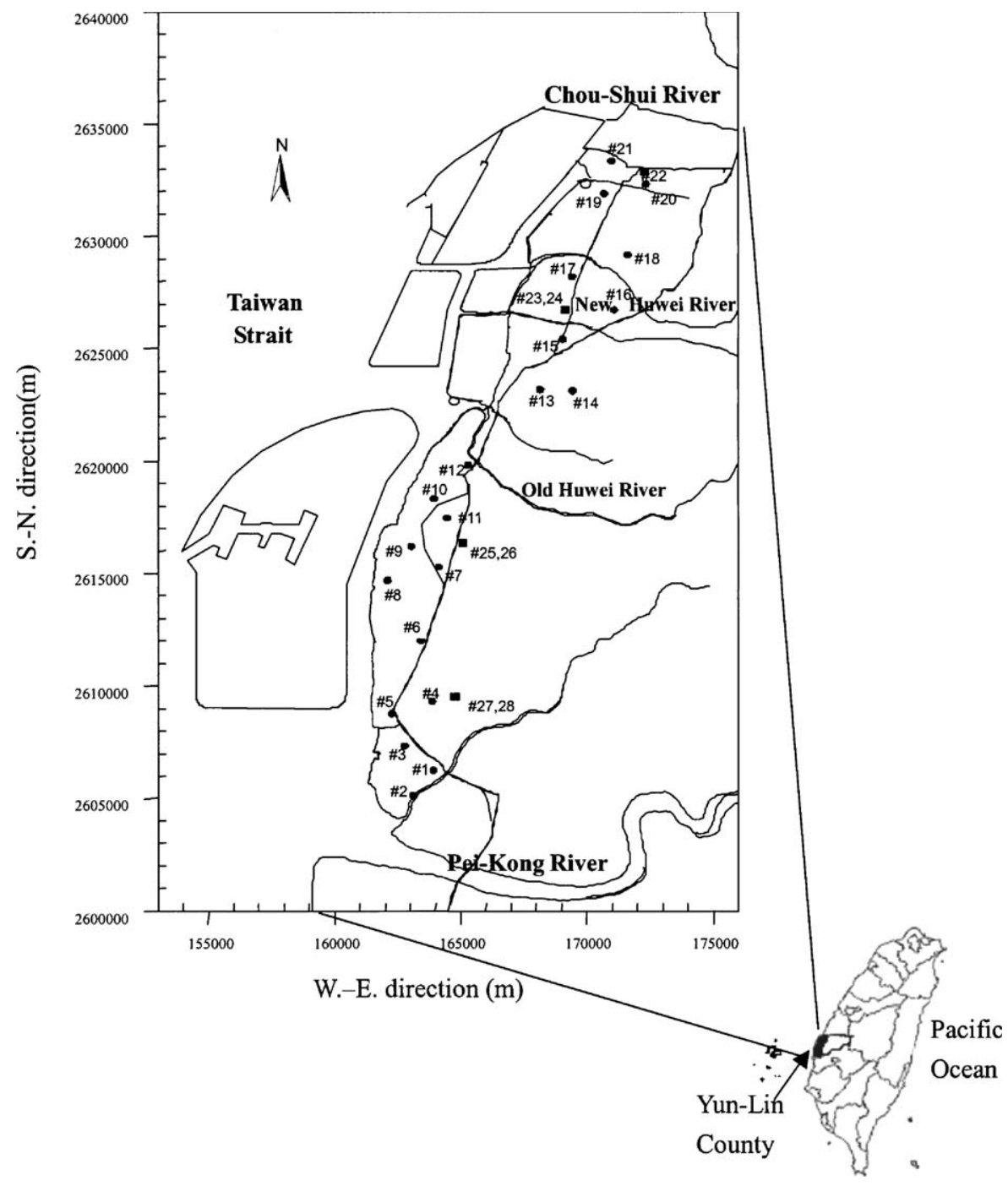

Fig. 1. Locations of 28 wells in Yun-Lin coastal area, Taiwan. 
Twenty-eight groundwater monitoring wells, including 21 shallow wells and seven deep wells have been constructed in the coastal blackfoot disease region of Yun-Lin (Fig. 1). These wells were designed to monitor the quality of groundwater, with an emphasis on arsenic pollutant and aquifer salinization. The depth of the wells ranges from 8 to $110 \mathrm{~m}$. Groundwater samples were collected seasonally between 1992 and 1998 [10], inclusive. A volume of groundwater, equal to that of three wells, was purged before sampling. Samples were then collected from the outflow of the well pump in polyethylene bottles. Unstable parameters, such as temperature and electrical conductivity (EC), were measured in the field. Other parameters, alkalinity (Alk), the concentrations of total dissolved solid (TDS), arsenic (As), total organic carbon (TOC), sulfates $\left(\mathrm{SO}_{4}^{2-}\right), \mathrm{Cl}^{-}, \mathrm{NO}_{3}^{-}-\mathrm{N}, \mathrm{Na}^{+}, \mathrm{K}^{+}, \mathrm{Mg}^{2+}$ and $\mathrm{Ca}^{2+}$, and the total hardness $(\mathrm{TH})$, were measured in the laboratory.

The complexity of the regional hydrogeological conditions is such that the hydrochemical processes that occur in the aquifers are difficult to explain and document, so the application of advanced statistical methods to simplify the model input is essential.

Factor analysis, a multivariate statistical method that yields a general relationship between measured chemical variables, can be used to assess the importance of each input parameter to ANN. Liu et al. [11] applied factor analysis to establish that the seawater salinization factor including concentrations of $\mathrm{EC}, \mathrm{TDS}, \mathrm{Cl}^{-}, \mathrm{SO}_{4}^{2-}, \mathrm{Na}^{+}$, $\mathrm{K}^{+}$, and $\mathrm{Mg}^{2+}$, and the arsenic pollutant factor including concentrations of Alk, TOC, and As, importantly influence the quality of groundwater in the coastal area of Yun-Lin. These two factors govern 77\% of the quality of groundwater and are selected for use in the ANN model to forecast the future variation of groundwater quality.

\section{Artificial neural network}

\subsection{Theory}

The back-propagation (BP) neural network, one ANN, is self-organizing, self-teaching and nonlinear. A typical three-layered feed-forward neural network is comprised of a multiple elements also called nodes, and connection pathways that links them $[12,13]$. The nodes are processing elements of the network and are normally known as neurons, reflecting the fact the neural network method model is based on the biological neural network of the human brain. A neuron receives an input signal, processes it, and transmits an output signal to other interconnected neurons.
In the hidden and output layers, the net input to unit $i$ is of the form

$s_{i}=\sum_{j=1}^{k} w_{j i} y_{j}+\theta_{i}$,

where $w_{j i}=\left(w_{1 i}, w_{2 i}, \ldots, w_{k i}\right)$ is the weight vector of unit $i$ and $k$ is the number of neurons in the layer above the layer that includes unit $i . y_{j}$ is the output from unit $j$, and $\theta_{i}$ is the bias of unit $i$. This weighted sum $s_{i}$, which is called the incoming signal of unit $i$, is then passed through a nonlinear transfer function $(f)$ to yield the estimates $\hat{y}_{i}$ for unit $i$.

Several types of transfer function are used; however, the most frequently used is the sigmoid function. This transfer function is usually a steadily increasing Sshaped curve. The sigmoid function is continuous, differentiable everywhere, and monotonically increasing. The sigmoid transfer function, $f_{i}$, of unit $i$, is of the form

$\hat{y}_{i}=\frac{1}{1+\mathrm{e}^{-\left(s_{i}\right)}}$.

These accumulated inputs are then transformed to the neuron output. This output is generally distributed to various connection pathways to provide inputs to the other neurons; each of these connection pathways transmits the full output of the contributing neuron.

\subsection{Training}

The training process determines the ANN weights and is similar to the calibration of a mathematical model. The ANNs are trained with a training set of input and known output data. At the beginning of training, the weights are initialized either with a set of random values, or based on some previous experience. The goal of learning is to determine a set of weights that will minimize the error function [14]. As training proceeds, the weights are systematically updated according to a training rule. Several training examples are presented to the network, and the process is terminated when the difference between measured and estimated value is less than a specified value. At this stage, the $\mathrm{ANN}$ is considered trained.

The network is trained to produce an estimated output vector $\hat{Y}(n)$ when presented with an input pattern $X(n)$. The error function at the $n$th input exemplar, $E(n)$, is given by

$E(n)=\frac{1}{2}(\hat{Y}(n)-Y(n))^{2}$,

where $\hat{Y}(n)$ is the estimated state of the output unit in response to the $n$th input exemplar and $Y(n)$ is the desired state of the output unit. After the $(n+1)$ th input exemplar is presented, the weight is generally update by

$\Delta w_{j i}(n+1)=-\eta \frac{\partial E}{\partial w_{j i}}-\xi \Delta w_{j i}(n)$, 
where $\eta$ represents the learning rate, which for practical purposes, is chosen as high as possible without causing the oscillation of the convergence of the network. $\xi$ is a constant (momentum term) that determines the effect of past weight changes on the current weight change.

\subsection{Evaluation of performance}

After the training is complete, the performance of the ANN is determined. Depending on the outcome, the ANN is either retrained or it applied as intended. The numbers of neurons in the input, output and hidden layers depend on the problem. If the number of hidden neurons is small, then the network may not have sufficient degrees of freedom to learn the process correctly. If the number is too high, the training will take a long time and the network may overfit the data [15].

The performance of the forecasting of both the training and the testing sets is evaluated by the following measure of goodness-of-fit, root mean squared error (RMSE)

$\mathrm{RMSE}=\sqrt{\frac{1}{M N} \sum_{m=1}^{M} \sum_{n=1}^{N}\left[\hat{Y}_{m n}-Y_{m n}\right]^{2}}$,

where $M$ is the number of estimated output; $N$ is the number of exemplar; $\hat{Y}_{m n}$ is the $m$ th estimated output value in the $n$th exemplar; $Y_{m n}$ is the $m$ th actual output value in the $n$th exemplar.

\subsection{Confidence and prediction intervals}

This study applies asymptotically valid prediction intervals [16] and constructed confidence intervals from the prediction intervals. Estimated confidence intervals are developed from a neural network, in which the number of neurons, $k$, is known. The observations $\left(Y_{i}\right.$, $\left.X_{i}\right)$, are assumed to satisfy

$Y_{i}=g_{\theta}\left(X_{i}\right)+\varepsilon_{i}$,

where $1 \leqslant i \leqslant n$. Let $Y_{n+1}$ denote a future unobservable datum that satisfies

$Y_{n+1}=g_{\theta}\left(X_{n+1}\right)+\varepsilon_{n+1}$.

Assume that the $X_{i}$ 's are independent of the $\varepsilon_{i}$ 's and that $\left(X_{i}, \varepsilon_{i}\right), 1 \leqslant i \leqslant n+1$, are independently, identically distributed; then a confidence interval is constructed for $g_{\theta}\left(X_{n+1}\right)$, the conditional mean of $Y_{n+1}$ given $X_{n+1}$. Moreover, $\hat{\theta}$ is assumed to be a consistent estimator of $\theta$, based on a sample size $n$ and

$\sqrt{n}(\hat{\theta}-\theta) \rightarrow N\left(0, \sigma^{2} V(\theta)\right)$,

where $\sigma^{2}$ is a scale parameter that can be consistently estimated by an estimator $\hat{\sigma}^{2}$, and $V(\theta)$ is a square matrix.

Let $\hat{\theta}$ be a global minimizer of $\sum_{i=1}^{n}\left(Y_{i}-g_{\hat{\theta}}\left(X_{i}\right)\right)^{2}$, which exists by compactness of $\theta$ and the continuity of $g$. Then

$g_{\hat{\theta}}\left(X_{n+1}\right) \pm\left[t_{1-\alpha / 2, n-(d+2) k-1}\right] \cdot \hat{\sigma} \sqrt{S(\hat{\theta})}$

is a confidence interval of $g_{\theta}\left(X_{n+1}\right)$ with an asymptotic coverage probability of $1-\alpha$. The target (desired) output of model is

$g_{\hat{\theta}}\left(X_{n+1}\right)=\alpha_{0}+\sum_{i=1}^{k} \alpha_{i} f\left(\beta_{1}^{\mathrm{t}} X_{n+1}+\beta_{i 0}\right)$,

where $\beta_{i}^{\mathrm{t}}=\left(\beta_{i 1}, \ldots, \beta_{i d}\right)$ and $\theta=\left(\alpha_{0}, \ldots, \alpha_{k}, \beta_{10}, \ldots\right.$, $\left.\beta_{k 0}, \beta_{1}^{\mathrm{t}}, \ldots, \beta_{k}^{\mathrm{t}}\right)$ are the weights or the unknown parameters, and the superscript t denotes the transpose. As proven by Cybenko [17], most functions (including any continuous function with a bounded support) can be approximated by functions of the form of Eq. (11); $\alpha_{1}, \ldots, \alpha_{k}$ are the weights that link the output layer and the hidden layer; $\alpha_{0}$ is bias in the output layer; $\beta_{10}, \ldots, \beta_{k 0}$ are biases in the hidden layer; $n$ is the number of training sets; $k$ is neurons in the hidden layer; $d$ is the number of neurons in the input layer, and $1-\alpha$ is the coefficient of confidence. $t_{1-\alpha / 2, n-(d+2) k-1}$ denotes the $1-\alpha / 2$ quartile of a $t$ distribution with $n-(d+$ $2) k-1$ degrees of freedom

$\hat{\sigma}^{2}=\frac{1}{n-(d+2) k-1} \sum_{i=1}^{n}\left(Y_{i}-g_{\hat{\theta}}\left(X_{i}\right)\right)^{2}$

and

$S(\hat{\theta})=\frac{1}{n}\left\{\left[\nabla_{\theta} g_{\theta}\left(X_{n+1}\right)\right]_{\theta=\hat{\theta}}^{\mathrm{t}} \hat{\Sigma}^{-1}(\hat{\theta})\left[\nabla_{\theta} g_{\theta}\left(X_{n+1}\right)\right]_{\theta=\hat{\theta}}\right\}$,

where

$\hat{\Sigma}^{-1}(\hat{\theta})=\left[\frac{1}{n} \sum_{i=1}^{n}\left[\nabla_{\theta} g_{\theta}\left(X_{i}\right) \nabla_{\theta} g_{\theta}\left(X_{i}\right)^{\mathrm{t}}\right]_{\theta=\hat{\theta}}\right]^{-1}$.

Furthermore, $\varepsilon_{n+1}$ is assumed to be normally distributed; then

$g_{\hat{\theta}}\left(X_{n+1}\right) \pm\left[t_{1-\alpha / 2, n-(d+2) k-1}\right] \hat{\sigma} \sqrt{1+S(\hat{\theta})}$

is an asymptotic prediction interval for $Y_{n+1}$. Hwang and Ding [16] thoroughly discussed these confidence intervals.

\subsection{Modeling}

An ANN software package, Qnet97 [18], is adopted herein the study. The requirements of the neural computation algorithm are such that raw data are usually normalized to an interval by transformation. The transformations modify the distribution of the input variables so that it matches the distribution of the estimated outputs. Herein, all input data are transformed to the same ground-uniform distributions on $[0.15,0.85]$.

In this study, wells with seriously contaminated groundwater were selected from north to south. Wells 
2, 8, 10 and 19 and wells 2, 7, 9 and 19 with seawater salinization, and arsenic pollutant, respectively, were used to evaluate the performance of the ANN models in assessing the variation of groundwater quality.

\section{Results and discussion}

Twenty-two seasonal data on the quality of groundwater over six-year monitoring period are prepared to train ANN. The last three seasonal data are used to verify the trained ANN model.

Three types of ANN structures are established to evaluate the learning performance of the training model. Model A uses five variables as input/output neurons for seawater salinization factor and three variables as input/ output neurons for arsenic pollutant factor. All variables are determined by factor analysis with a single season of data set for training. Models B and C use a single variable as an input/output neuron but model $\mathrm{B}$ was trained by a single seasonal datum whereas model $\mathrm{C}$ was trained with two seasonal data. Table 1 presents ANN models and the parameters used to assess seawater salinization and arsenic pollutant factors. The numbers of hidden neurons range from 2-12, 1-3 and 2-4 for models A, B and C, respectively. Only the number of hidden neurons that yields the minimum training RMSE is presented for each model. The training RMSE reflects the repeat feature of an ANN model, while, the testing RMSE reflects the generalization feature. Thus, the accuracy of the model can be determined from the testing RMSE.

\subsection{Model performance}

The concentrations of $\mathrm{EC}, \mathrm{Cl}^{-}, \mathrm{SO}_{4}^{2-}, \mathrm{K}^{+}$, and $\mathrm{Mg}^{2+}$ which determine seawater salinization, were selected from seven variables, to evaluate the performance of model A. Since $\mathrm{Na}^{+}$and $\mathrm{Cl}^{-}$are closely related as a pair electrolytes, only $\mathrm{Cl}^{-}$was included in model A. Three variables, Alk, As and TOC, that determine the arsenic pollutant factor, were included to evaluate the performance of the ANN model.

Table 2 illustrates the training and testing results of model A used to model seawater salinization and arsenic pollutant factors. For the seawater salinization factor, well 10 yielded the minimum testing RMSE, whereas well 2 yielded the largest training and testing RMSEs. Furthermore, the groundwater in well 2 was more seriously salinized than that in any of the other 27 wells. The future variation in concentration by seawater salinization in the most polluted well, well 2, are of interest. Accordingly, the groundwater concentrations of wells 2 and 10 were thus adopted to models B and C, to predict future variations in concentration by seawater salinization. With reference to arsenic pollutant, well 9 showed the worst arsenic pollutant and had the smallest training and testing RMSEs, while well 19 had the largest testing RMSE. Models B and C were used to determine the variation of concentration the arsenic pollutant factor in wells 9 and 19. Table 3 presents the training and testing results of models $\mathrm{B}$ and $\mathrm{C}$ for seawater salinization and arsenic pollutant factors. The testing RMSEs of all variables in Model $\mathrm{C}$ are smaller than those in Model B. The mean testing RMSEs obtained by models $\mathrm{A}, \mathrm{B}$ and $\mathrm{C}$ were compared to determine the ANN performance in these models. Table 4 presents the mean testing RMSE of models A, B and C. Model C has the smallest mean testing RMSE among the three models. Model C outperforms models A and B.

The training RMSE was compared with the testing RMSE (Table 4) to measure the training performance of ANN model $\mathrm{C}$. In well 2, according to model $\mathrm{C}$, the training RMSEs of $\mathrm{EC}, \mathrm{Cl}^{-}, \mathrm{K}^{+}$and $\mathrm{Mg}^{2+}$ were

Table 2

Training and testing results obtained by model A for seawater salinization and arsenic pollutant factors

\begin{tabular}{lrrll}
\hline Factor & Well No. & Neurons & \multicolumn{2}{l}{ RMSE } \\
\cline { 3 - 5 } & & & Training & Testing \\
\hline Seawater & 2 & 5 & 0.084 & 0.160 \\
salinization & 8 & 5 & 0.082 & 0.097 \\
& 10 & 12 & 0.072 & 0.064 \\
& 19 & 10 & 0.051 & 0.067 \\
Arsenic & 2 & 3 & & \\
pollutant & 7 & 3 & 0.123 & 0.170 \\
& 9 & 2 & 0.109 & 0.158 \\
& 19 & 3 & 0.118 & 0.187 \\
\hline
\end{tabular}

Table 1

ANN models and the parameters used to specify seawater salinization and arsenic pollutant factors

\begin{tabular}{|c|c|c|c|c|c|c|}
\hline Model & $\begin{array}{l}\text { Input } \\
\text { number of } \\
\text { variables }\end{array}$ & Function of model & $\begin{array}{l}\text { Number of } \\
\text { hidden neurons }\end{array}$ & $\begin{array}{l}\text { Learning number } \\
\text { (Unit: } 10,000)\end{array}$ & $\begin{array}{l}\text { Number of training } \\
\text { exemplars }\end{array}$ & $\begin{array}{l}\text { Number of } \\
\text { testing exemplars }\end{array}$ \\
\hline A & 5 or 3 & $X_{i}(t)=f\left[X_{i}(t-1)\right]$ & $5-12$ or $2-6$ & $5-15$ & 22 & 3 \\
\hline B & 1 & $X(t)=f[X(t-1)]$ & $1-3$ & $10-25$ & 22 & 3 \\
\hline $\mathrm{C}$ & 1 & $X(t)=f[X(t-1), X(t-2)]$ & $2-4$ & $20-40$ & 21 & 3 \\
\hline
\end{tabular}


Table 3

Training and testing results obtained by models $\mathrm{B}$ and $\mathrm{C}$ for seawater salinization and arsenic pollutant factors

\begin{tabular}{|c|c|c|c|c|c|c|c|c|}
\hline \multirow[t]{3}{*}{ Factor } & \multirow[t]{3}{*}{ Well No. } & \multirow[t]{3}{*}{ Variables } & \multicolumn{3}{|l|}{ Model B } & \multicolumn{3}{|l|}{ Model C } \\
\hline & & & \multirow[t]{2}{*}{ Neurons } & \multicolumn{2}{|l|}{ RMSE } & \multirow[t]{2}{*}{ Neurons } & \multicolumn{2}{|l|}{ RMSE } \\
\hline & & & & Training & Testing & & Training & Testing \\
\hline \multirow{10}{*}{$\begin{array}{l}\text { Seawater } \\
\text { salinization }\end{array}$} & \multirow[t]{5}{*}{2} & EC & 3 & 0.110 & 0.095 & 3 & 0.069 & 0.091 \\
\hline & & $\mathrm{Cl}^{-}$ & 1 & 0.118 & 0.113 & 3 & 0.074 & 0.109 \\
\hline & & $\mathrm{SO}_{4}^{2-}$ & 1 & 0.113 & 0.128 & 3 & 0.105 & 0.072 \\
\hline & & $\mathrm{K}^{+}$ & 1 & 0.079 & 0.232 & 3 & 0.067 & 0.208 \\
\hline & & $\mathrm{Mg}^{2+}$ & 1 & 0.070 & 0.185 & 3 & 0.052 & 0.173 \\
\hline & \multirow[t]{5}{*}{10} & $\mathrm{EC}$ & 1 & 0.093 & 0.057 & 4 & 0.060 & 0.061 \\
\hline & & $\mathrm{Cl}^{-}$ & 2 & 0.067 & 0.019 & 3 & 0.001 & 0.001 \\
\hline & & $\mathrm{SO}_{4}^{2-}$ & 3 & 0.035 & 0.065 & 3 & 0.024 & 0.060 \\
\hline & & $\mathrm{K}^{+}$ & 3 & 0.104 & 0.018 & 3 & 0.114 & 0.015 \\
\hline & & $\mathrm{Mg}^{2+}$ & 1 & 0.064 & 0.058 & 3 & 0.058 & 0.052 \\
\hline \multirow{6}{*}{$\begin{array}{l}\text { Arsenic } \\
\text { pollutant }\end{array}$} & \multirow[t]{3}{*}{9} & Alk & 1 & 0.106 & 0.051 & 2 & 0.107 & 0.050 \\
\hline & & TOC & 1 & 0.120 & 0.086 & 3 & 0.075 & 0.068 \\
\hline & & As & 2 & 0.104 & 0.067 & 3 & 0.054 & 0.067 \\
\hline & \multirow[t]{3}{*}{19} & Alk & 1 & 0.117 & 0.033 & 2 & 0.111 & 0.033 \\
\hline & & TOC & 2 & 0.123 & 0.178 & 4 & 0.145 & 0.164 \\
\hline & & As & 1 & 0.087 & 0.177 & 3 & 0.108 & 0.150 \\
\hline
\end{tabular}

Table 4

Mean testing RMSE of seawater salinization and arsenic pollutant factors obtained by models $\mathrm{A}, \mathrm{B}$, and $\mathrm{C}$

\begin{tabular}{|c|c|c|c|c|}
\hline \multirow[t]{3}{*}{ Model } & \multicolumn{4}{|c|}{ Mean testing RMSE } \\
\hline & \multicolumn{2}{|c|}{ Seawater salinization } & \multicolumn{2}{|c|}{ Arsenic pollutant } \\
\hline & Well 2 & Well 10 & Well 9 & Well 19 \\
\hline A & 0.160 & 0.064 & 0.078 & 0.187 \\
\hline B & 0.151 & 0.043 & 0.068 & 0.129 \\
\hline C & 0.131 & 0.038 & 0.062 & 0.116 \\
\hline
\end{tabular}

smaller than the corresponding testing RMSEs indicating that the models had not been adequately generalized, perhaps because insufficient testing exemplars or training exemplars were used during the learning process of the ANN. Box-and-whisker plots (Fig. 2) illustrate the most forecasted values of the testing exemplars in well 2 exceed the box limit $(25-75 \%)$ or the highest concentrations of the training exemplars.

The training and testing RMSEs of all seawater salinization variables in well 10 , and those of TOC and As in arsenic pollutant factor in well 9 were similar indicating that the ANN models were well trained and fully generalized. The box-and-whisker plot (Fig. 2) also showed that the forecasted values of the testing exemplars in wells 10 and 9 were all within the box limits and did not exceed the highest concentration of the training exemplars.
In well 9 according to model $\mathrm{C}$, the training RMSE $(0.107)$ of Alk is much larger than the testing RMSE (0.050), suggesting that Alk according to model C is not generalized. The training exemplars cannot be well correlated, perhaps because the fifth seasonal concentration was much smaller than the other seasonal concentrations and the training exemplars were too few. In well 19, the training and testing RMSEs of TOC and As both exceed 0.10, indicating the trained models of TOC and As were far from being generalized, which fact maybe also follow from the too low number of training exemplars and large variations in concentrations of As and TOC in the testing exemplars.

The effect of the number of neurons in the hidden layer on model performance is considered. Fig. 3 plots the number of hidden neurons against the training and testing RMSEs in wells 2, 10, 9 and 19, according to model A. The results show that the number of hidden neurons used in the model did not affect the training and testing RMSEs. Increasing the number of hidden neurons did not improve the forecasting by the model.

Table 5 presents descriptive statistics of concentration variables in the four wells. The coefficient of variation (CV) of the concentration variables in well 10 all exceed those in well 2, but most of the training and testing RMSEs of concentration variables in well 10 are less than those in well 2 (Table 3). Fig. 4a plots the seasonal concentration variations of well 10 , indicating that concentrations change greatly during the 13th season. Accordingly, the CV-value of each concentration variable before and after 13th season was calculated. The 

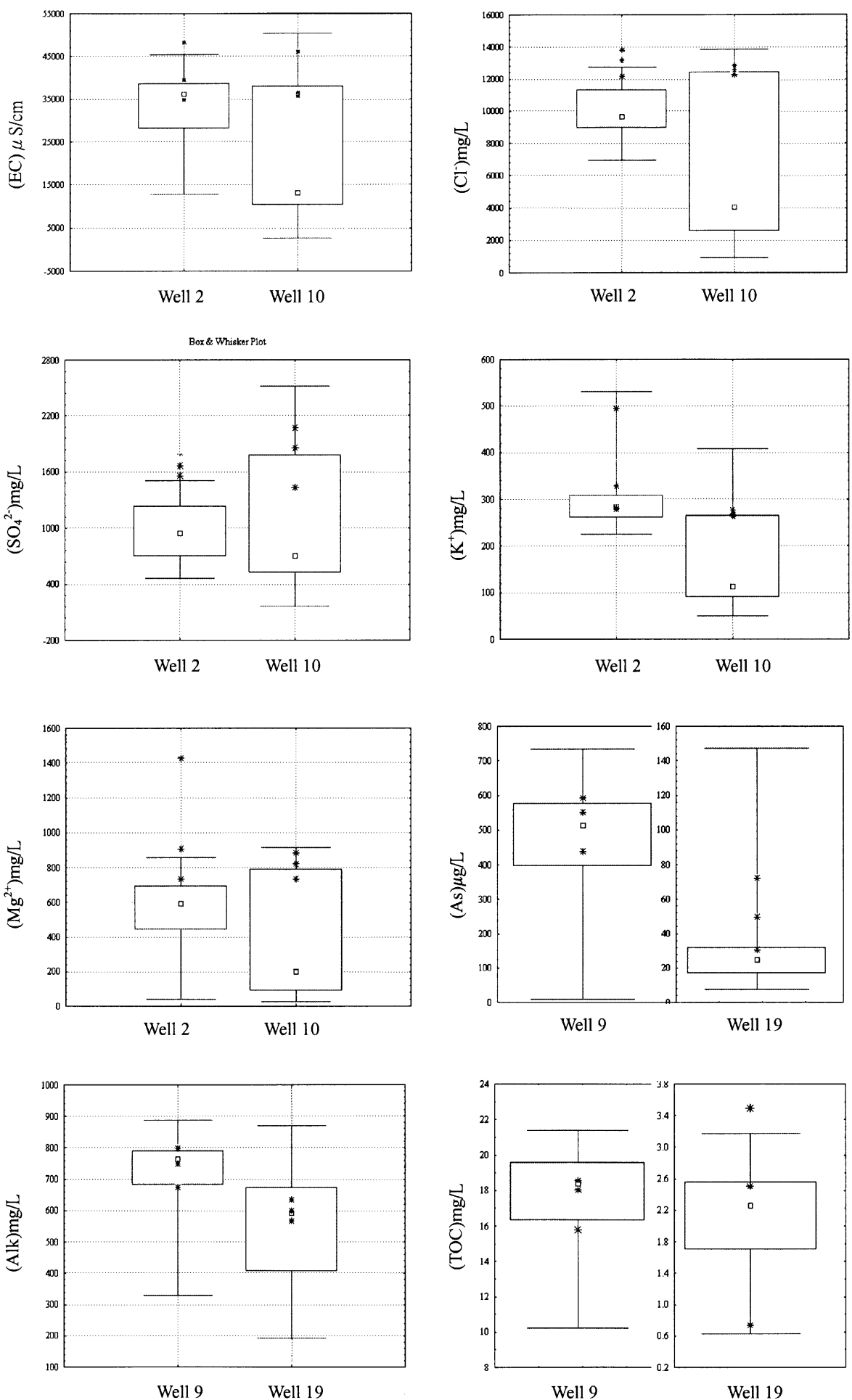

Fig. 2. Box-and-whisker plot of training exemplars of wells 2, 10, 9 and 19. Stars and the square denote testing exemplars and the median, respectively. The central box represents the lower and upper quartiles ( 25 and 75 percentile). Two horizontal bars denote the minimum and the maximum measured concentrations. 

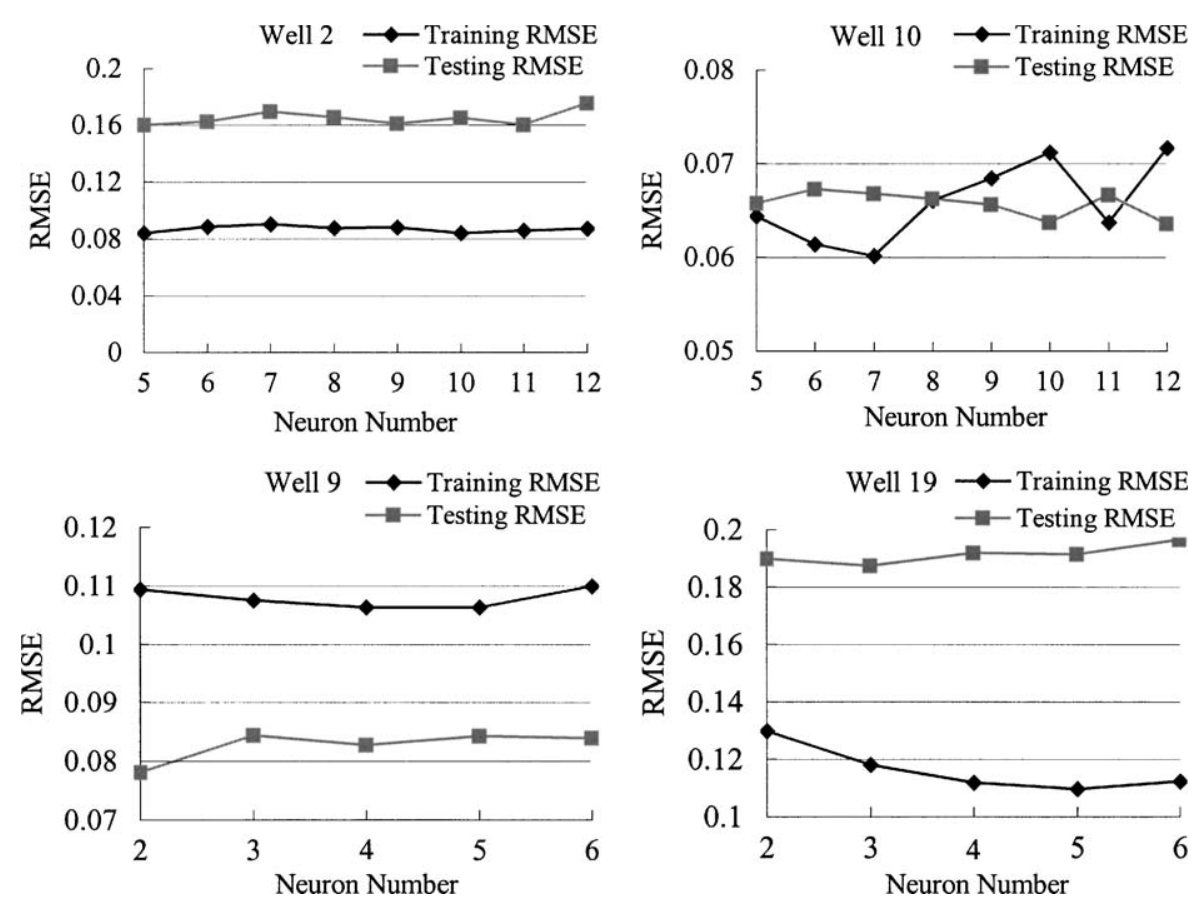

Fig. 3. Number of hidden neurons versus training and testing RMSEs in wells 2, 10, 9 and 19 obtained by model A.

Table 5

Descriptive statistics of the measured concentrations of seawater salinization and arsenic pollutant factors in wells 2, 10, 9 and 19

\begin{tabular}{|c|c|c|c|c|c|c|c|}
\hline Well & Variables & Mean & $\mathrm{SD}^{\mathrm{a}}$ & $\mathrm{CV}(\%)^{\mathrm{b}}$ & CV(\%) 1-13th & $\mathrm{CV}(\%)$ 14-21th & Average $\mathrm{CV}(\%)^{\mathrm{c}}$ \\
\hline \multirow[t]{5}{*}{2} & $\mathrm{EC}(\mu \mathrm{S} / \mathrm{cm})$ & 33,842 & 7858 & 23.22 & - & - & - \\
\hline & $\mathrm{Cl}^{-}(\mathrm{mg} / \mathrm{L})$ & 9933 & 1693 & 17.04 & - & - & - \\
\hline & $\mathrm{SO}_{4}^{2-}(\mathrm{mg} / \mathrm{L})$ & 958 & 295 & 30.75 & - & - & - \\
\hline & $\mathrm{K}^{+}(\mathrm{mg} / \mathrm{L})$ & 294 & 60 & 20.32 & - & - & - \\
\hline & $\mathrm{Mg}^{2+}(\mathrm{mg} / \mathrm{L})$ & 554 & 208 & 37.59 & - & - & - \\
\hline \multirow[t]{5}{*}{10} & $\mathrm{EC}(\mu \mathrm{S} / \mathrm{cm})$ & 21,334 & 16,530 & 77.48 & 44.24 & 14.11 & 29.17 \\
\hline & $\mathrm{Cl}^{-}(\mathrm{mg} / \mathrm{L})$ & 6280 & 4732 & 75.35 & 37.56 & 9.53 & 23.54 \\
\hline & $\mathrm{SO}_{4}^{2-}(\mathrm{mg} / \mathrm{L})$ & 1008 & 701 & 69.55 & 42.23 & 16.14 & 29.18 \\
\hline & $\mathrm{K}^{+}(\mathrm{mg} / \mathrm{L})$ & 171 & 100 & 58.69 & 37.37 & 17.91 & 27.64 \\
\hline & $\mathrm{Mg}^{2+}(\mathrm{mg} / \mathrm{L})$ & 367 & 342 & 93.14 & 52.02 & 18.43 & 35.22 \\
\hline \multirow[t]{3}{*}{9} & As $(\mu \mathrm{g} / \mathrm{L})$ & 456 & 221 & 48.56 & - & - & - \\
\hline & Alk (mg/L) & 695 & 167 & 24.09 & - & - & - \\
\hline & TOC (mg/L) & 17.66 & 2.95 & 16.70 & - & - & - \\
\hline \multirow[t]{3}{*}{19} & As $(\mu \mathrm{g} / \mathrm{L})$ & 30.1 & 27.3 & 90.86 & - & - & - \\
\hline & Alk (mg/L) & 554 & 174 & 31.44 & - & - & - \\
\hline & TOC $(\mathrm{mg} / \mathrm{L})$ & 2.09 & 0.69 & 33.08 & - & - & - \\
\hline
\end{tabular}

${ }^{\mathrm{a}} \mathrm{SD}$ : standard deviation,

${ }^{\mathrm{b}} \mathrm{CV}$ : coefficient of variation,

${ }^{\mathrm{c}}$ Average $\mathrm{CV}(\%)=(\mathrm{CV}(\%) 1-13 \mathrm{th}+\mathrm{CV}(\%) 14-21 \mathrm{th}) / 2$.

results showed that the $\mathrm{CV}$-value of each concentration variable in seasons 14-21 was much smaller than that in seasons 1-13 (Table 5), and that the average CV-values in seasons 1-13 and seasons 14-21 (last column in
Table 5) are much smaller than the CV-value across all 21 seasons (fifth column in Table 5). The statistics on the prediction by the ANN model depend mainly on the structure of the time series data. A box-and-whisker plot 

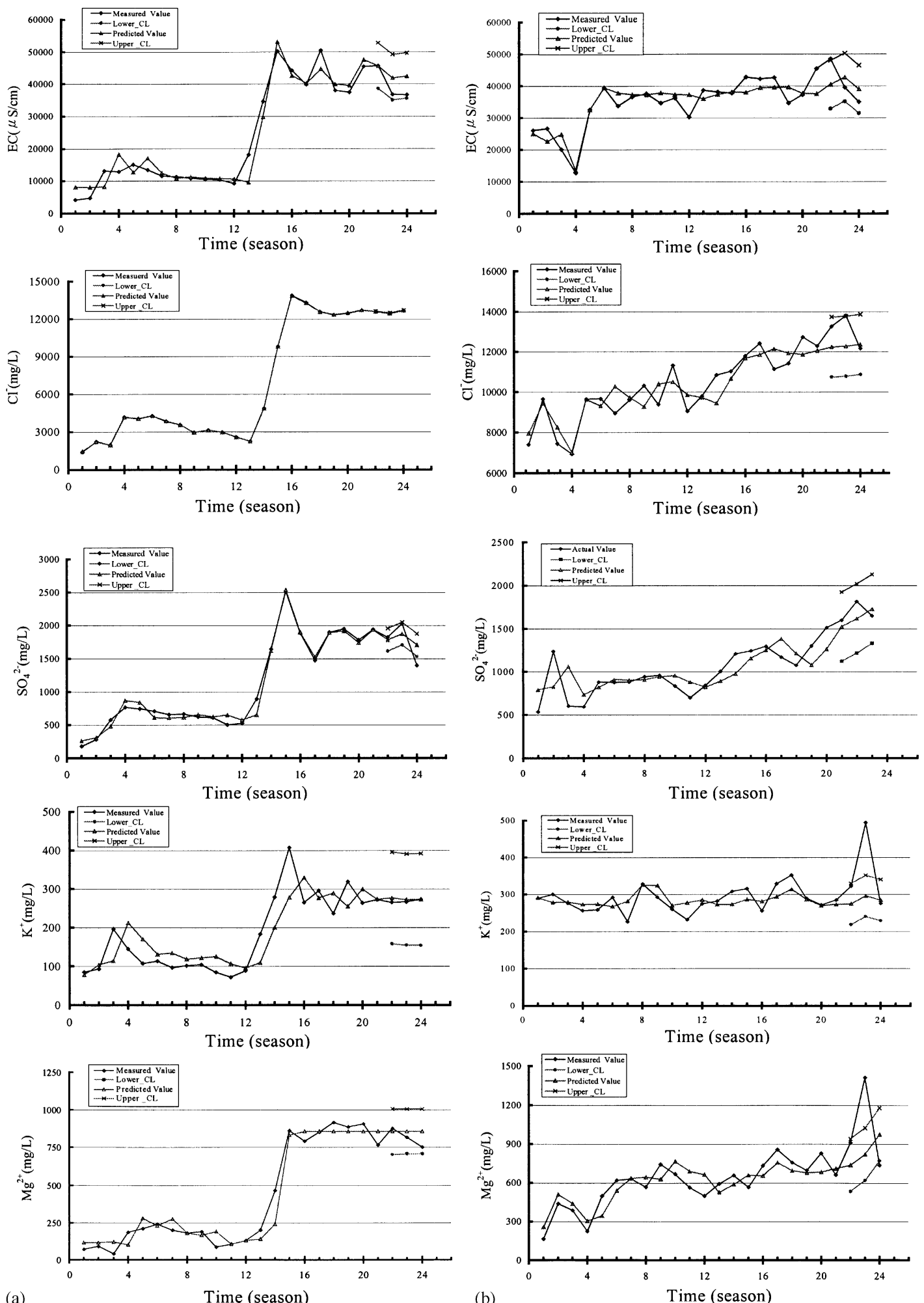

(a)

Time (season)

(b)

Fig. 4. Estimated confidence interval of concentrations $\mathrm{EC}, \mathrm{Cl}^{-}, \mathrm{SO}_{4}^{2-}, \mathrm{K}^{+}$and $\mathrm{Mg}^{2+}$ in: (a) well 10 and (b) well 2. 
(Fig. 3) also revealed that if the testing exemplar exceeds the limit set by the box, the model yields a high testing RMSE, such as that of the concentration in well 2.

\subsection{Confidence interval}

The mean testing RMSEs obtained by model $\mathrm{C}$ are lower than those obtained by models $\mathrm{A}$ and $\mathrm{B}$, suggesting that the use of data from two previous seasons in ANN model training yields better results than the use of data from only one season. Model $\mathrm{C}$ was adopted to compute the confidence interval of the variation of concentration.

Fig. 4 plots the $90 \%$ confidence intervals of concentration variables that affect seawater salinization factor in wells 10 and 2. Only three data exemplars are
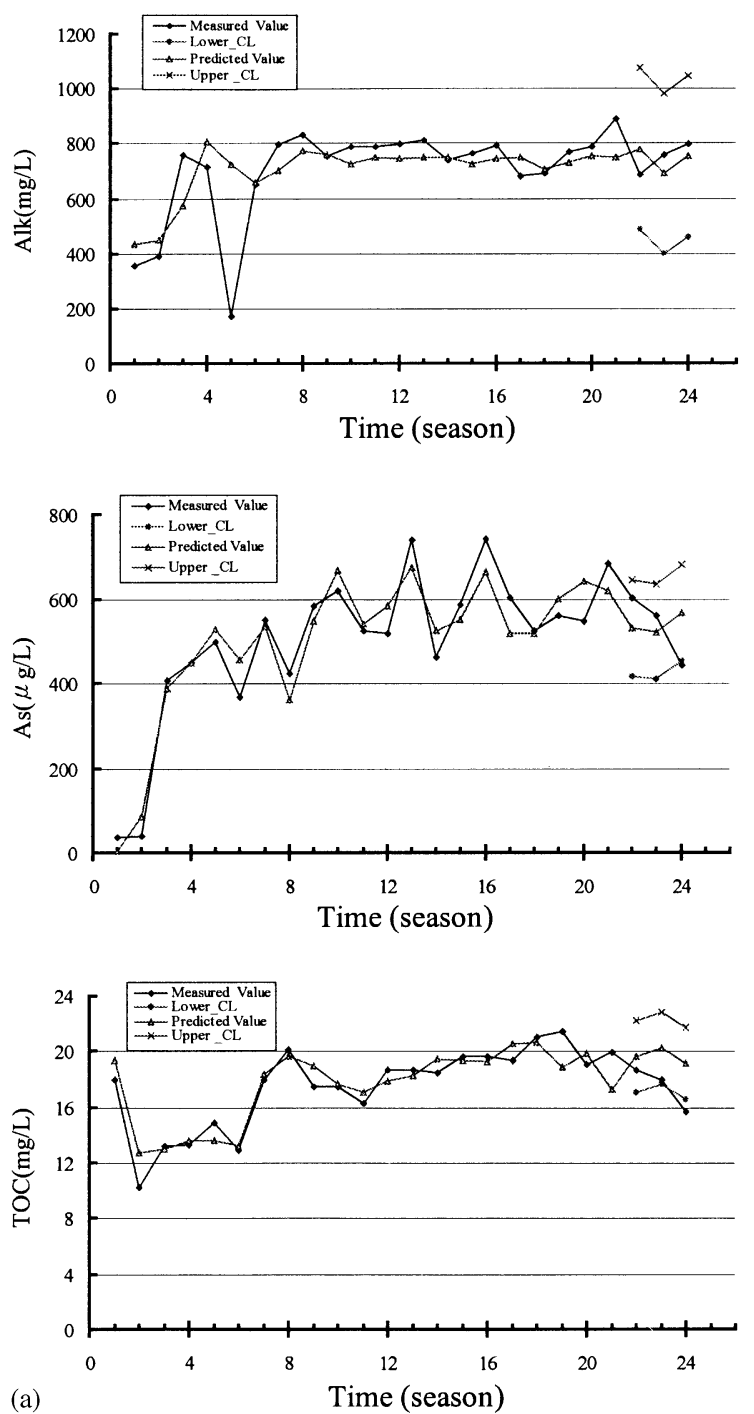

Fig. 5. Estimated confidence interval of concentrations Alk, As and TOC in: (a) well 9 and (b) well 19. available for testing the model. If the measured concentration variables vary greatly, then the testing RMSE increases. However, well the model is trained with small variance, the forecasted concentrations may not fall within the $90 \%$ confidence interval if the testing data exhibit a large variation in concentration. In well 2 , the measured water concentration values vary considerably in the testing seasons and some forecasted concentration values fall outside the $90 \%$ confidence interval. The measured water concentration values in well 10, varied less than those in well 2 in the testing seasons, and the forecasted water concentration values were thus are all within the $90 \%$ confidence interval.

Fig. 5 plots the concentration variables, in the $90 \%$ confidence interval, that affect arsenic pollutant in wells 9 and 19. The forecasted trends in concentration trends
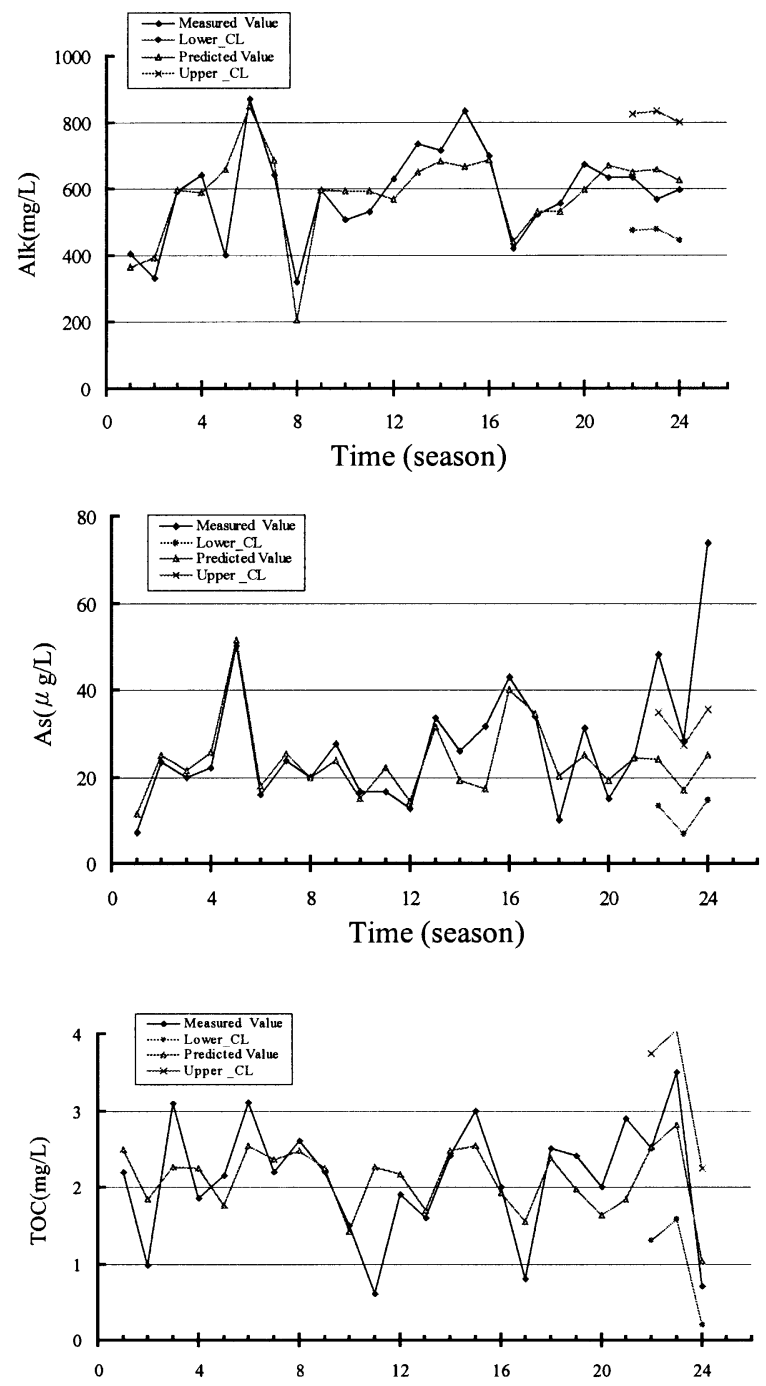

(b)

Time (season) 
are not accurately identified because the testing data vary wildly. In well 9, the measured concentrations of As and TOC in the last testing season lied slightly outside the $90 \%$ confidence interval, but did not exceed the largest concentrations of As and TOC in the training seasons. In well 19, the two testing exemplars of measured As concentrations fell outside the 90\% confidence interval and the As concentration in last testing season exceeded the largest As concentration in the training seasons (Fig. 5b); therefore, the model yielded a high testing RMSE. The results suggest that the ANN model $\mathrm{C}$ performs with limited success in forecasting future seasonal concentrations when the future concentrations vary wildly.

\section{Conclusions}

BP of ANN model was adopted to evaluate the performance of the ANN model in assessing the variation in groundwater quality caused by seawater salinization and arsenic pollutant factors, as derived by factorial analysis. Three types of models of the BP ANN were established to evaluate the learning performance of the training model. Model A included five concentration parameters as input variables to determine seawater intrusion and three to determine arsenic pollutant, respectively, whereas models $\mathrm{B}$ and $\mathrm{C}$ used only one concentration parameter for each. Moreover, model C used data from two seasons to train the ANN whereas models A and B used only data from one season. The analytical results indicate that the mean testing RMSE value obtained by model $\mathrm{C}$ is lower than that obtained by models A and B. Model C outperforms models A and B. Model $\mathrm{C}$ included current and previous data as inputs and can describe the complex variation of groundwater quality yielding the optimum prediction. If the training set includes the maximum and minimum data values, then the model will yield satisfactory forecast that falls within the $90 \%$ confidence interval. Moreover, as the number of hidden neurons increases, the testing and training RMSEs do not significantly decrease. Increasing the number of training and testing exemplars will cause the ANN model to receive sufficient training and yield satisfactory a testing RMSE.

\section{Acknowledgements}

The authors would like to thank the National Science Council of the Republic of China for financially supporting this research under Contract No. NSC 912313-B-002-270.

\section{References}

[1] Cabrera-Mercader CR, Staelin DH. Passive microwave relative humidity retrievals using feedforward neural network. IEEE Trans Geosci Remote Sens 1995;33(6):842-52.

[2] Raman H, Chandramouli V. Deriving a general operating policy for reservoirs using neural networks. J Water Resour Plan Manage ASCE 1996;122(5):342-7.

[3] Lek S, Guiresse M, Giraudel JL. Predicting stream nitrogen concentration from watershed features using neural networks. Water Res 1999;33(16):3469-78.

[4] Wen CW, Lee CS. A neural network approach to multiobjective optimization for water quality management in a river basin. Water Resour Res 1998;34(3):427-36.

[5] Rogers LL, Dowla FU. Optimization of groundwater remediation using artificial neural networks with parallel solute transport modeling. Water Resour Res 1994;30(2):457-81.

[6] Tsao YS, Wang JL. A comprehensive study of sea water intrusion for the Yun-Lin aquifer system. Agricultural Engineering Research Center, Taiwan; 1984. p. 159.

[7] Shen SB. Study on land subsidence in coastal plains in Yun-Lin area (I). Conference on Land Subsidence, Taiwan; 1989. p. 191-211.

[8] Chen CJ, Hsueh YM, Lai MS, Shyu MP, Chen SY, Wu MM, Kuo TL, Tai TY. Increased prevalence of hypertension and long-term arsenic exposure. Hypertension 1995;25:53-60.

[9] Lin MC, Liao CM, Liu CW, Singh S. Bioaccumulation of arsenic in aquacultural large-scale mullet Liza macrolepis from blackfoot disease area in Taiwan. Bull Environ Contam Toxicol 2001;67:91-7.

[10] Tainan Hydraulic Laboratory. The Yun-Lin offshore industrial infrastructure complexes planning, development and monitoring report, Part I, vol. 6, Groundwater level and quality measurements. National Cheng-Kung University, Taiwan, ROC, 1992-1998.

[11] Liu CW, Lin KH, Kuo YM. Application of factor analysis in the assessment of groundwater quality in a blackfoot disease area in Taiwan. Sci Total Environ 2003;313 (1-3):77-89.

[12] Hagan MT, Demuth H, Beale M. Neural network design. 20 Park Plaza, Boston, MA: PWS Publishing Company; 1995.

[13] Haykin S. Neural network-a comprehensive foundation. Englewood Cliffs, NJ: Prentice-Hall; 1999.

[14] Garson GD. Interpreting neural network connection weights. A.I. Expert 1991;6:47-51.

[15] Karunanithi N, Grenney WJ, Whitley D, Bovee K. Neural networks for river flow prediction. J Computation in Civil Engineering, ASCE 1994;8(2):210-20.

[16] Hwang GJT, Ding AA. Prediction intervals for artificial neural networks. J Am Stat Assoc 1997;92(438):748-57.

[17] Cybenko G. Approximation and superpositions of a sigmoidal function. Math Contr Sig Syst 1989;2:303-14.

[18] Qnet 97. Neural Network Modeling for Windows 95/98/ NT. Vesta Services, Inc Winnetka, IL, 1997. 